\title{
El kérygma de Creonte y el ideal de la obediencia absoluta al derecho en Tebas: una lectura iusfilosófica de Antígona de Sófocles*
}

\author{
Creon's kerygma and the ideal of absolute obedience to the law \\ in Thebes: a legal-philosophical reading of Sophocles' Antigone
}

EDUARDO ESTEBAN MAGOJA**

\begin{abstract}
Resumen: En Antígona de Sófocles, Creonte sanciona un decreto (kérygma) con el fin de regular jurídicamente una situación especial en las tierras de Tebas: prohibir que se dé sepultura al cuerpo del traidor Polinices. A partir de un enfoque iusfilosófico, en este trabajo se estudiará en especial la fuerza obligatoria de esa norma y el ideal de Creonte de alcanzar obediencia absoluta en la pólis. El propósito será demostrar cómo el rey de Tebas espera obtener sumisión a su autoridad a través del miedo a la sanción jurídica. Los valores y otros intereses sociales son por lo general descuidados u ocupan un lugar secundario.

Palabras clave: obediencia-derecho-sanción jurídica.
\end{abstract}

\section{Introducción}

Hegel (2007 [1807], 261-283) en Fenomenología del espíritu afirma que Antígona representa el conflicto entre la ley del Estado y el derecho de la familia ${ }^{1}$. Tanto Antígona como Creonte defienden principios fundamentales y, por eso, actúan con corrección; sin

Recibido: 29/08/2016. Aceptado: 11/04/2017.

* $\quad$ Este trabajo fue realizado en el marco del Proyecto de Investigación UBACYT (convocatoria 2016-2018) “Cuerpos poéticos. Discursos y representaciones de la corporalidad en el mundo griego antiguo", dirigido por la Dra. Elsa Rodríguez Cidre y codirigido por el Dr. Emiliano J. Buis, y también del Proyecto de Investigación PICT2014-0615 (convocatoria 2015-2018 Temas abiertos-Tipo A) "Expresiones literarias del imaginario familiar en la Atenas clásica: integración y marginalidad en los vínculos de parentesco”, dirigido por la Dra. Viviana Gastaldi.

** Docente de Teoría General y Filosofía del Derecho de la Universidad de Buenos Aires. E-mail: magojaeduardo@gmail.com.

1 La visión de Hegel se encuentra también expuesta en sus obras posteriores Elementos de la filosofía del derecho (1821), Lecciones sobre filosofía de la religión (1832) y Lecciones sobre estética (1842). 
embargo, como son unilaterales en la defensa de estos principios, al mismo tiempo están equivocados. Esta lectura fijó una línea interpretativa de corte iusfilosófico que mantienen numerosos autores ${ }^{2}$, según la cual se cree que en la tragedia existen dos legalidades distintas y en oposición: por un lado, la ley divina o natural y, por el otro, la ley humana o secular ${ }^{3}$. Sin embargo, frente a esta visión algunos autores han intentado demostrar que, si se considera la naturaleza de las instituciones legales de la Atenas clásica, aquel conflicto no debe entenderse tan así $1^{4}$.

Uno de los principales exponentes de esta postura ha sido Harris (2004). Este autor ha demostrado con sólidos argumentos que, si bien existe un enfrentamiento normativo, no debe pensarse estrictamente como una tajante oposición entre la ley divina y la ley de la ciudad o, en términos iusfilosóficos, entre el derecho natural y el derecho positivo. En Antígona existen varios elementos discursivos, retóricos e institucionales que permiten tener una lectura distinta. A partir de un minucioso análisis del texto y de un estudio de los lexemas de carácter jurídico que se utilizan, Harris (2004, 48-49) afirma que el nómos ("ley”) que invoca Antígona es una norma que expresa no sólo lo divino, sino también el consenso, las costumbres y los valores básicos de la comunidad. En contraposición, la norma que invoca Creonte no es un nómos, sino un simple kérygma ("decreto") que sólo encuentra sustento en su cargo ${ }^{5}$.

Siguiendo esta interpretación que ve el conflicto de Antígona como la oposición entre el kérygma de Creonte y el nómos de Antígona, en este trabajo se estudiará en especial la fuerza obligatoria de la norma del rey de Tebas y el ideal que tiene de obtener obediencia absoluta $^{6}$. Este es un aspecto que por lo general la literatura no ha abordado en detalle, pero sobre el cual es importante reflexionar a los fines de tener una mayor comprensión del problema iusfilosófico de la obra. Se trata de explorar en el discurso poético la cuestión de las razones por las cuales se debe obedecer la norma del rey en el marco del razonamiento práctico, es decir, el razonamiento destinado a elegir un curso de acción.

2 Como destaca Goldhill $(1986,88)$, desde la lectura que hizo Hegel de la tragedia, es muy difícil no considerar a Antígona en términos de dialéctica y oposición.

3 Esta oposición legal se advierte en los trabajos de Knapp (1916), Jaeger (2010 [1933], 259-260), Errandonea (1942, 304), Boyd (1952), Adams (1955), Levy (1963), Segal (1964 y 1999 [1981], 169), Plescia (1976), Eggers Lan (1986, 42), Goldhill (1986, 96-97), Pinkler \& Vigo (1994, 48 y ss.), Thomas (1996, 17), Tiefenbrun (1999), Picco (1999, 93-94), Soares (2002, 106 y ss.), Rosenfield (2002), Parodi Remón (2004), Boedeker \& Raaflaub (2005, 119-120), Orsi (2007, 237-238), Mastromarco \& Toraro (2008, 104), Santamaría (2009, 85), Robert (2010), Schere (2011, xxxvii), de Oliveira (2013), entre otros. Por su parte, Ferguson (1974-1975) considera que el agón es entre dos percepciones antitéticas de la justicia (dike).

4 Cf. Cerri (1979, 13); Lane \& Lane (1986, 168); Lanza (1997, 97); Burns (2002); de Romilly (2004, 27); Carter (2012, 123-125). Nonet (2006), por ejemplo, sostiene que la ley de Antígona no sólo es no escrita, sino indecible. A ella se encuentran sometidos tanto los dioses como los hombres y la forma correcta de nombrarla es mediante la palabra phýsis. Según el autor este término es intraducible y no debe ser confundido de ningún modo con el derecho natural. Finalmente, Antígona no la conoce a partir de ninguna experiencia pasada ni tampoco en virtud de una reflexión del problema; esto es una cuestión que reside más bien en el resplandor de su ser. La propia esencia de la heroína está determinada por su obediencia a esa ley.

5 Cf. Harris $(2004,41)$.

6 En este estudio, el texto base que se utiliza corresponde a la edición de Pearson (1957). La edición de los otros autores clásicos es aquella consignada en la bibliografía, en el apartado correspondiente. Todas las traducciones del griego al español me pertenecen. 
Intentaré demostrar cómo en Antígona el rey espera obtener obediencia absoluta de sus requerimientos principalmente a través del miedo a la sanción jurídica. Los valores u otros intereses sociales, en este sentido, son por lo general descuidados por Creonte a la hora de exigir que se cumpla con aquello que sus normas disponen. O, en todo caso, se puede decir que sólo tienen un papel superficial en su discurso. Esto es precisamente lo que lleva a Creonte a su propia destrucción, es decir, su hýbris en materia de obediencia al derecho.

\section{Las razones prudenciales y la pretensión de autoridad del kérygma de Creonte}

Existen distintas clases de razones para actuar en el razonamiento práctico que justifican de manera distinta la obligación de obedecer el derecho. Una de ellas son las razones prudenciales. Este concepto expresa la idea de que el individuo obedece el derecho porque el mal que eventualmente sufriría con la aplicación de la sanción jurídica supera los beneficios que obtendría de violar la norma. Este es uno de los razonamientos más comunes y difundidos dentro de la teoría jurídica. Ya Antifonte decía que los individuos obedecen el nómos, en presencia de testigos, porque de no hacerlo sufrirían un castigo ${ }^{7}$. Gran parte de los representantes del contractualismo, como Hobbes (2007 [1651], 147-148), u otros autores canónicos de la filosofía del derecho, como Austin (1998 [1832]), 14-15) o von Wright $(1970,139)$, consideran que el miedo al castigo es un medio eficaz para lograr que los individuos se abstengan de realizar una conducta disvaliosa o, en algunos casos, para promover la realización de una conducta jurídicamente deseable.

El derecho funciona por lo general de este modo o se presenta con esta estructura. Por ejemplo, la mayoría de las normas jurídicas que pertenecen al campo del derecho penal aspiran a proteger bienes jurídicos que son considerados valiosos, como la vida, la libertad o la integridad física, mediante la aplicación de una sanción negativa (castigo). Sin embargo, éste no es el único medio dentro de la técnica legislativa para incentivar la realización de una conducta. Además de sanciones negativas también las normas pueden establecer sanciones positivas (premios).

El uso de castigos y premios es una característica muy propia del fenómeno jurídico y concebir el concepto de derecho sin la idea de sanción parece algo muy difícil de aceptar. Sólo en una sociedad de ángeles, como la que imagina Raz (1999, 159-160), las normas jurídicas no necesitarían de sanciones. No así en el mundo terrenal, donde los conflictos sociales están latentes y la amenaza de la sanción constituye motivo de obediencia frente a otros motivos que puedan alentar a los individuos a transgredir las normas. Quizás la explicación canónica de derecho establecida por el más importante e influyente jurista de los últimos siglos pueda ser muy iluminadora. Me refiero, por supuesto, a la formulación de Kelsen (2011 [1934], 59-60), quien sostiene que el derecho, considerado en cuanto a su fin, constituye una técnica social específica que permite motivar a los hombres a comportarse de

7 En la visión de Antifonte (DK 44 A) los mandatos de la naturaleza (phýsis) ordenan obtener la mayor cantidad de beneficios posible. Si alguien transgrede la ley (nómos) y su acción es advertida por testigos (mártyroi), será castigado y no obtendrá ninguna ventaja. El temor a la sanción de la ley, pues, se vuelve la justificación de su obediencia. Al respecto, ver Rivas Palá (1996, 187-201), Bieda (2008). 
determinada manera a través del acto coactivo ${ }^{8}$. La coacción o la privación de un bien es visto por los destinatarios de las normas como un mal muy serio y, por eso, se trata de evitar.

En Antígona, la forma mediante la cual Creonte espera que los ciudadanos se sometan al kérygma que prohíbe dar sepultura al difunto Polinices sigue de cerca esta mecánica. El miedo a la sanción es una técnica privilegiada para la conducción del gobierno. Esto precisamente se puede ver en el discurso de Ismene, en el comportamiento del Coro, en las acusaciones que le dirige Antígona al gobierno de Creonte y también en los reproches que le hace su hijo Hemón. Veamos cada una de estas instancias en el orden señalado.

Ya se sabe desde el inicio de la obra que Antígona heroicamente desobedecerá la norma del nuevo soberano de Tebas que prohíbe dar sepultura a Polinices. Sin embargo, no sucederá lo mismo con Ismene. Ella tiene varios pretextos por los cuales dice que se someterá sin más al kérygma: en primer lugar, recuerda cómo murió su padre, odiado y deshonrado después de quitarse la vista a causa de crímenes que él mismo había cometido; luego, la muerte de la madre y esposa de Edipo, quien se quitó la vida ahorcándose; finalmente, la muerte de sus hermanos, quienes se asesinaron mutuamente (vv. 49 y ss.).

La referencia constante que hace Ismene a la muerte de sus familiares, tiene como propósito trazar una comparación con el modo en que ella y Antígona morirían si transgreden

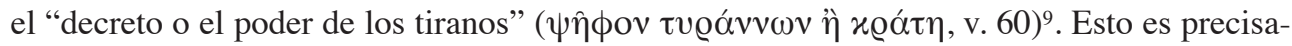

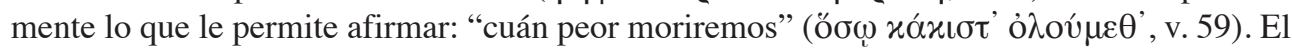
trágico destino que señala Ismene está asociado con la sanción que Creonte había establecido para los infractores: "muerte por lapidación pública en la ciudad" ( $\phi o ́ v o v . . \delta \emptyset \mu o ́ \lambda \varepsilon v \sigma \tau o v$

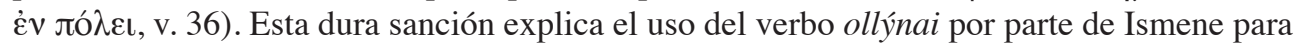
referirse a la consecuencia que sufrirán en caso de violar la norma. En efecto, este verbo, en voz media, si bien tiene el sentido básico de "perecer", "fallecer" o "morir", también tiene un sentido especial que se ajusta con mayor exactitud al significado de las palabras de Ismene, que es "morir de manera violenta" 10 .

Sin duda la muerte por lapidación es un modo violento de dejar la vida. Pero no sólo eso, sino que además es una pena que no estaba institucionalizada ni tampoco amparada por la ley. En realidad, en la Atenas antigua, según explica Cantarella (1996, 68 y ss.), la lapidación expresaba el sentido espontáneo de vengarse de alguien que había cometido un hecho criminal gravísimo ${ }^{11}$. Era un acto de venganza que no representaba la voluntad oficial

8 En igual sentido, ver Kelsen (1949, 19-20 y 1994 [1953], 72-74).

9 Es conveniente realizar en esta instancia una breve explicación de la semántica del concepto de týrannos a los fines de evitar malentendidos. En efecto, los especialistas sostienen que durante los siglos VII y VI a. C. týrannos era un término neutro que respondía a la situación social, económica y política de un momento histórico concreto y que se utilizaba como sinónimo de basileús ("rey") o ánax ("señor"). De hecho, V. Parker (1998) afirma que el uso indistinto entre los términos siguió estando presente a lo largo del siglo V a. C. y en especial en el género trágico. Sin embargo, otros autores, como Seaford (2003) y Raaflaub (2003), creen que los poetas, influenciados por el nuevo contexto político democrático, recogieron también en sus composiciones otra connotación más ligada con el aspecto negativo de la tiranía. En este trabajo se seguirá la regla general de que el término no presenta ningún sentido peyorativo, sino neutro y denota la idea de "rey", "gobernante" o "el que tiene el mando". Sin embargo, en algunas ocasiones se hará uso de su valencia negativa, en especial cuanto el rey cae en hýbris y administra la pólis de un modo desviado y corrupto.

10 Cf. Liddell \& Scott (1996) s.v. ő $\lambda \lambda v \mu$ t.

11 Cf. Cantarella (1996, 68-69). 
del grupo, sino que manifestaba una especie de justicia popular impulsada por las pasiones y en la que predominaba la idea de devolver mal por mal ${ }^{12}$. Esta (ir)racionalidad es lo que se advierte en el caso particular de Antígona. En efecto, si bien la muerte por lapidación parece ser una pena institucionalizada, ya que está prescripta por el soberano de Tebas, lo cierto es que no deja de ser un castigo ligado con las pasiones y los extremismos del rey ${ }^{13}$. Es una medida extraordinaria que se emplea en una situación especial y que tiene como último fin aterrorizar al pueblo para conseguir obediencia. De hecho, la técnica que utiliza Creonte logra efectivamente conseguir ese resultado con Ismene ${ }^{14}$. La obediencia y la sobrevivencia serán sus últimos valores ${ }^{15}$.

Hay que considerar, con respecto al temor que busca infundir Creonte, que las hijas de Edipo son mujeres que han quedado "solas" ( $\mu$ óv $\alpha$, v. 58) y que en el marco de un sistema patriarcal deben evitar cualquier disputa o enfrentamiento con los hombres. Según dice Ismene, su condición las obliga a cumplir con todas las órdenes de quienes gobiernan, ya que son más poderosos (vv. 61-64). En este sentido, Ismene no considera estar moralmente obligada a obedecer el decreto de Creonte, sino que -dice ella- "estoy forzada a eso"

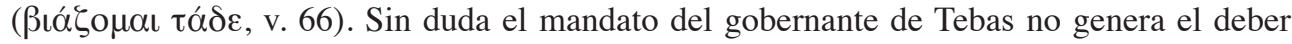
de obediencia en Ismene porque sea justo o satisfaga, en última instancia, intereses valiosos para la comunidad: la única garantía que tiene para motivar la obediencia es la terrible pena que dispone.

La sumisión de Ismene al kérygma de Creonte en virtud del miedo al castigo aflorará de un modo más patente cuando es acusada por el rey de participar en el entierro de Polinices. En el segundo episodio, ella expresa su deseo de morir junto a Antígona y compartir su mismo destino y, por eso, alega ser cómplice de la acción criminal. Sin embargo, la heroína deja en claro que jamás Díke se lo permitirá, pues nunca fue su intención querer sepultar a su hermano (vv. 538-539). Ella eligió la vida antes que la muerte (v. 555). De hecho, cuando Ismene le pregunta a Antígona cómo podrá amar la vida si ella muere, la heroína le responde de un modo muy irónico: "pregúntale a Creonte, pues tú [eres] quien se preocupa

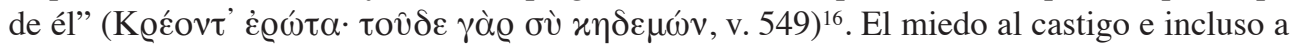
la tiranía fue una razón que sobrepasó el deseo de Ismene de cumplir con los ritos fúnebres de su hermano. En el razonamiento destinado a elegir un curso de acción, el temor al castigo impidió que aquélla transgreda la norma impuesta por Creonte. Así demostró, en las propias palabras de Antígona, ser una cobarde (v. 38).

El miedo a la severa pena también se vislumbra en la comunidad de Tebas. La primera ocasión en la cual se advierte esto es cuando Creonte convoca a la asamblea de ancianos (vv. 163 y ss.) y les comunica la decisión que ha adoptado con respecto a los cadáveres de

12 Este aspecto puede advertirse en diferentes fuentes del género trágico. Cf. A. $A$ (vv. 1612-1616); S. $A j$. (v. 254) y $O C$ (vv. 433-436); E. $T r$. (vv. 1039-1041), IA (v. 1350), Or. (vv. 57 y ss.), Ba. (vv. 352-357), Ion (vv. 1111$1112,1222-1225$ y $1238-1241)$.

13 Esto mismo se puede ver en A. Th. (vv. 181-199).

14 Cf. García-Huidobro $(1998,92)$.

15 Cf. Lane \& Lane $(1986,167)$.

16 Tyrrell \& Bennett (2008-2009) han advertido a partir de esta clase de enfrentamientos entre Antígona e Ismene cómo Sófocles inserta el conflicto dentro de la oposición lógos/érgon. En esta oportunidad, Ismene intenta coincidir con su hermana en el plan del lógos pero falla; al principio de la obra Antígona intenta lo mismo en el campo del érgon y también fracasa. Las hermanas no pueden, pues, cooperar mutuamente. 
Eteocles y Polinices. En efecto, en esa instancia expresa ciertas dudas acerca de que efectivamente se cumplan sus órdenes (vv. 215 y ss.). En virtud de ello, exige al Coro que vigile lo ordenado y que no ceda frente a quienes desobedezcan (v. 219) ${ }^{17}$. Esta actitud insistente y sumamente dura en el ejercicio del poder da cuenta de cómo Creonte sabe que es el miedo lo que contiene a los ciudadanos. De hecho, una vez que el rey pronuncia esas órdenes, el Coro confirma que el temor al castigo es la garantía para evitar todo acto de desobediencia,

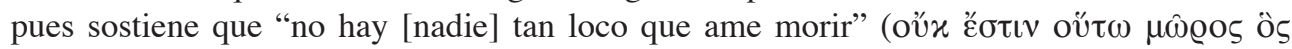

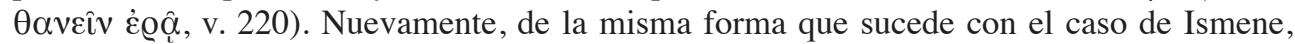
la posibilidad de morir, especialmente de morir por lapidación pública, aparece como la principal razón que vence, en la deliberación racional, a cualquier otro tipo de razón que pudiera inducir a los ciudadanos a realizar la conducta prohibida por el mandato de Creonte.

La actitud del dêmos también se muestra a través de las palabras de Antígona y Hemón. Sus discursos dejan entrever cuáles son las razones de los cadmeos que justifican el deber de obedecer el kérygma soberano. En el instante en que Antígona es acusada por Creonte de haber desobedecido su mandato, manifiesta dos veces el temor que tiene el pueblo a la tiranía. En la primera ocasión, según la heroína se podría decir que "a todos" ( $\tau \hat{\alpha} \sigma \iota v, v$.

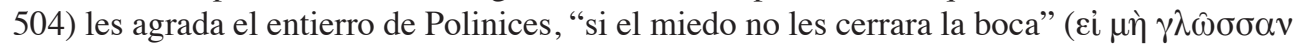
$\dot{\varepsilon} \gamma \varkappa \lambda$ ṇo $\phi o ́(0 \varsigma$, v. 505); en la segunda, afirma de nuevo que en presencia de Creonte "esos"

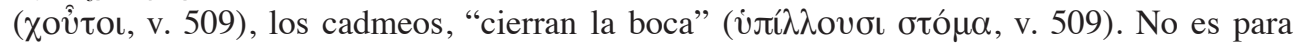
nada casual que también Hemón, de un modo muy similar al expresado por Antígona, dé a conocer el temor que tienen los ciudadanos al poder tiránico. Precisamente sostiene que el

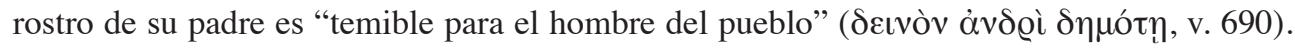

El temor silencia, no deja expresar la verdadera opinión del pueblo acerca del decreto que regula la situación de los fallecidos hijos de Edipo. Esto no es un aspecto menor, ya que se trata de ciudadanos que no pueden hacer uso del lógos, el instrumento de poder más importante en la pólis democrática y la herramienta necesaria para participar en la vida política y en la toma de decisiones públicas. Aristóteles (Pol. 1253a9-18) decía que el hombre es el único de los animales que tiene lógos y que, por eso, se diferenciaba de los demás, que tienen simplemente phoné. Mediante la phoné, que carece por sí misma de significado ${ }^{18}$, los animales pueden manifestar el dolor o el placer, pero los hombres, al disponer a su vez de lógos, tienen la exclusiva capacidad de expresar lo ventajoso y lo perjudicial, y también lo justo y lo injusto.

Los ciudadanos de Tebas son hombres que han llegado al extremo de no poder hacer uso de este lógos: el miedo a la tiranía mantiene sus bocas cerradas y les impide emitir cualquier opinión o juicio de valor de forma pública ${ }^{19}$. El poder autocrático de Creonte ha rebajado a los cadmeos a una condición que se torna contradictoria con la propia noción de ciudadano, de ese varón libre e igual que participa en la vida pública a través del lógos. Esto es algo que seguramente habría inquietado a los espectadores de la tragedia: la presencia de ciudadanos que están

17 Incluso se percibe aquí, como advierte Adams $(1955,51)$, el temor de Creonte, como un típico tirano, de que el edicto emitido sea la excusa para la stásis.

18 Así pues, Aristóteles (GA 786b21-22) nos dice que "la phoné es la materia del lógos" (

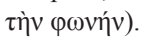

19 El mandato de Creonte estableció una regla bien clara para los ciudadanos: hay que mantenerse en silencio o bien expresar una opinión diferente que los llevará a la muerte. Cf. Worman (2012, 332-333). 
ausentes del campo político. No hay dudas de que en el gobierno de Creonte la sumisión a la norma se vuelve la regla general en el comportamiento de aquellos que se hallan bajo su órbita. El acto coactivo del tirano logra ser motivo de obediencia. En términos jurídicos la norma es eficaz, pues los destinatarios estiman que hay un considerable riesgo de sufrir el mal con el que se los amenaza ${ }^{20}$. Sólo hay -según dice Creonte- unos pocos hombres que "murmuraban"

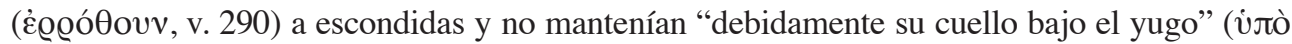

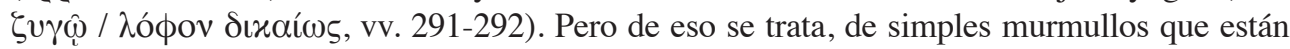
muy lejos de jugar en la escena política; no hay pues, un sentido fuerte de disenso ciudadano, ni en palabras ni mucho menos en hechos. Es Antígona quien únicamente carga con esa tarea, y su acto de desobediencia solitario es lo que resalta justamente su carácter heroico.

\section{El ideal de la obediencia absoluta en el discurso de Creonte}

Antígona es la representación más excelsa de la obediencia absoluta al basileús/týrannos. Una vez que Creonte promulga su kérygma, exige la obediencia incondicional de su norma por parte de todos los miembros de la pólis. O lo que es lo mismo, considera que no hay ninguna causa que justifique moralmente desobedecer la prohibición de dar sepultura a Polinices. En efecto, luego que Antígona es descubierta en flagrante violación del decreto y es llevada ante el soberano, expone los motivos que la impulsaron a desoír el mandato. De los argumentos que instala como para justificar su conducta, ninguno ha tenido el peso suficiente para lograr que el tirano ceda en la imposición de la pena: ni el valor de los nómoi ágraphoi y la necesidad de dar sepultura a los muertos (vv. 450-470) ni el fuerte vínculo fraternal que la une con el difunto (vv. 511 y ss.). Tampoco ha tenido tanta importancia para Creonte el hecho de que con la ejecución de la pena privará a su hijo Hemón de su prometida (vv. 568-576). Está claro que para el tirano de Tebas su ley es el criterio último e insuperable del bien y del mal y toda conducta que la desafíe no puede ser más que castiga. Esto lo convierte, naturalmente, en un gran adepto del positivismo ideológico, es decir, en aquella teoría iusfilosófica que sostiene que el derecho es, por el solo hecho de existir, un valor positivo y por eso los individuos deben obedecer todas las normas jurídicas ${ }^{21}$.

Inmediatamente después del agón entre Antígona y Creonte, Hemón entra en escena con el propósito de lograr que su padre modifique su decisión de ejecutar la pena de muerte dispuesta en la norma. En esta instancia de la obra es interesante ver que, antes de que Hemón pudiera pronunciarle cualquier palabra a su padre, éste ya directamente le pregunta si acaso se presenta enojado como consecuencia de escuchar la "irrevocable sentencia" ( $\tau \varepsilon \lambda \varepsilon i ́ \alpha v$ $\psi \hat{\eta} \phi o v$, v. 632) que ha recaído sobre su futura esposa (v. 633). En términos procesales, Creonte ha juzgado sobre el asunto y la sentencia pasó a autoridad de cosa juzgada: no existe, pues, ningún medio de impugnación que permita rever lo resuelto.

En el hecho de mantener incólume esa decisión final se pone en juego la supremacía de la autoridad y el ejercicio incondicional del krátos tyrannikón. Creonte se impone como un déspota que no admite ninguna excepción a las disposiciones de sus normas: ni siquiera su propio hijo está exento de ser afectado por las consecuencias que se derivan de la estricta

20 von Wright $(1970,140)$.

21 Cf. Bobbio (1965, 53); Ross (2008, 213). 
aplicación del kérygma. En la visión jurídica de la tiranía hay una premisa básica: si alguien transgredió su decreto, debe sufrir el castigo establecido en la norma. No aplicar la sanción mostraría a Creonte como un gobernante "mentiroso frente al pueblo" ( $\psi \varepsilon v \delta \hat{. . . . \tau o ́ ~} \lambda \varepsilon$ เ, v. 657) -para decirlo con sus propias palabras-. En este sentido, la actitud de Creonte está ligada con la timé personal y, aún más, con la cuestión de la correcta administración del grupo familiar. En efecto, Creonte sostiene que aquel que mantenga el buen orden sobre los de su propia estirpe y sea honesto en el campo privado, también será visto como justo en el plano político de la ciudad (vv. 659-671). El argumento es sumamente adecuado y persuasivo, ya que en el imaginario social de la Atenas clásica se consideraba que el ciudadano que no podía administrar su propio ôkkos tampoco podría manejarse adecuadamente en los espacios públicos ${ }^{22}$. Creonte traslada al campo político de la pólis el mismo paradigma que rige las relaciones familiares en el seno del ô̂kos: la mujer debe obedecer a su esposo (v. 678) y el hijo debe obedecer a su padre (vv. 639-644) ${ }^{23}$.

El punto que hay que tener presente, con respecto a la fuerza y el uso de este argumento, es que Creonte no es simplemente un pariente más de Antígona, sino la cabeza del grupo familiar, su señor y dueño. Es su kýrios y, como tal, el encargado en alimentarla, cuidarla, educarla y también ejercer la disciplina. Este rol que tiene Creonte con respecto a Antígona, que por cierto es muy importante en el seno de la familia griega, explica seguramente su necesidad de castigarla para dar el ejemplo a la ciudad. Si Creonte dispensara a Antígona del crimen cometido por cuestiones de afinidad familiar, su autoridad en el campo político se vería endeble, vulnerable y correría el riesgo de ser rebajada por los particulares, ya que -como vimos- la forma de ejercer el poder sobre los miembros del ốkos se refleja directamente sobre el plano más amplio de la pólis.

En la concepción política griega, si bien el ô̂kos estaba bajo el mando del kýrios, la estructura de la pólis democrática carecía naturalmente de esta figura. Sin embargo, en el marco de la tragedia Creonte se ve a sí mismo como kýrios de toda la ciudad de Tebas. Así pues, del mismo modo que en la familia este cargo implica un poder casi absoluto sobre aquellos que se hallan bajo su poder, en la concepción de Creonte los miembros de la pólis deben obedecer incondicionalmente las decisiones jurídicas que adopta ${ }^{24}$. No importa cuál sea el contenido de esa decisión, ya que, a su modo de ver, "a quien la ciudad designa [como autoridad], es necesario obedecerlo en las cosas pequeñas, en las justas y en las contrarias" (òv

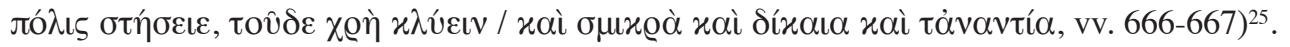

\section{El gobierno de la obediencia en Tebas}

La exigencia de obediencia absoluta, si bien pareciera que responde sólo al capricho del rey, también está ligada a fomentar y conservar el buen orden (eunomía). Si se tiene en cuenta este dato a la hora de juzgar su actitud, uno podría decir que después de todo no es tan mal gobernante: en cierto sentido, es un fiel defensor del ideal de preservar el orden

22 Aeschin. 1.30 y 3.78; P1. Plt. 259b9-10; X. Mem. 3.4.12 y 3.6.14; Arist. EN 1180b3-5.

23 Cf. Rehm $(2006,196)$.

24 Tanto en la familia como en la pólis la lealtad hacia quien ejerce el poder es condición para mantener la membresía en el grupo. Cf. Knox $(1964,89)$.

25 Cf. Blundell (1989, 123-124). 
jurídico y hacer valer la autoridad del derecho. El problema es que quiere imponen su derecho de cualquier modo y, al hacerlo, termina por transitar un camino moral y jurídicamente incorrecto. Es el camino de la hýbris, del ejercicio de la injusticia, de la falta de respeto por los dioses y de la trasgresión de otros tantos valores del mundo griego.

En su discurso inaugural, Creonte expresa frente a la asamblea de ancianos cómo la tormenta que azotaba la ciudad ha cesado y los dioses han traído calma al suelo tebano. En razón de ello, Creonte espera mantener este nuevo rumbo que navega la pólis. La clave acerca de cómo logrará ese fin descansa en preservar el orden social restablecido a través de la obediencia a las normas. En efecto, en la explicación de por qué convocó la asamblea, Creonte introduce un argumento retórico que busca confirmar su autoridad y también obtener legitimidad. Se trata de la estricta obediencia y lealtad que ellos tuvieron con el gobierno de Layo y también con el de Edipo. El nuevo rey espera obtener del pueblo la misma sumisión a la autoridad. Sin duda, Creonte logra alcanzar ese resultado, ya que los ciudadanos jamás manifiestan en ese espacio de deliberación pública ninguna objeción en cuanto a su asunción como gobernante. Sí es cierto, como advierte Harris (2004, 41-42), que ellos expresan ciertas dudas sobre el kérygma (vv. 211-212). Pero está claro que aquello que los ciudadanos ponen en duda es el decreto, no el cargo de gobernante.

De acuerdo con las nuevas responsabilidades asumidas, Creonte no exige obediencia por cuestiones secundarias, sino en razón de valores muy importantes, como la preservación de la armonía y, sobre todo, la conservación de la integridad patriótica del cuerpo de ciudadanos $^{26}$. En esta empresa no parece desacertado negar sepultura a un traidor a la patria. Es el ejemplo patriótico que muestra que aquel que violente a sus propios conciudadanos y quiebre la paz social, no tendrá ningún tipo de consuelo. En este orden de ideas, la ley de Atenas que prohibía dar sepultura a los traidores en el suelo ático cobra sentido ${ }^{27}$ y explica en algunos puntos los motivos que impulsaron a Creonte a sancionar su kérygma. Sin embargo, la razón de ser de esa clase de nómos no explica, en su totalidad, la exagerada y desmedida decisión del tirano. La conducta de Creonte va mucho más lejos que el verdadero sentido de la prohibición legal ateniense ${ }^{28}$, pues procura que el cuerpo de Polinices no sólo quede insepulto, sino que también sea devorado y despedazado por animales ${ }^{29}$.

El ideal de mantener el orden social por parte de Creonte llega a su punto más alto en el diálogo que mantiene con su hijo Hemón. En su visión filosófica-política, el mayor mal es la anarkhía (v. 672). Ésta destruye las “ciudades" (

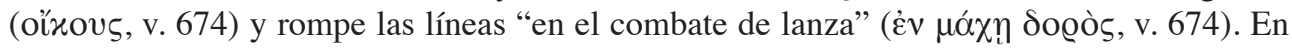

26 De hecho, la lealtad a la pólis que expone Creonte en su discurso inicial de los vv. 163-210 es un aspecto que fue admirado por el propio Demóstenes (19. 247). Esto ha llevado a Bowra (1944, 68) y a Knox $(1964,181 \mathrm{n}$. 52) a afirmar que las palabras de Creonte de los vv. 175-190, citadas por el gran orador ateniense, fueron muy bien recibidas por parte del auditorio. Incluso otros intérpretes, como Sourvinou-Inwood $(1989,135$ y 2005, 8) y Foley $(1995,144)$, en un sentido más extremo, dicen que aquel pasaje ejemplifica la ideología de la pólis y el patriotismo democrático.

27 Esta ley de Atenas está atestiguada en Tucídides (1.138.6) y Jenofonte ( $H G$ 1.7.22).

28 En efecto, de acuerdo con la ley era lícito negarle sepultura al traidor en su tierra natal, pero nada impedía que fuera enterrado más allá de los límites de la ciudad. En Jenofonte ( $H G$ 1.7.22) claramente se dice que la prohibición del entierro es sólo en suelo ático.

29 Es por eso que probablemente el acto haya sido muy perturbador para el público. Cf. R. Parker (1996, 47). 
cambio, aquello que salva la vida es la peitharkhía (v. 676) ${ }^{30}$. El uso de este vocablo tiene un sentido muy especial en la obra ${ }^{31}$. En los diccionarios especializados ${ }^{32}$ y léxicos de Sófocles $^{33}$ se ofrece como traducción posible del término "obediencia al mandato", "obediencia a las autoridades" o simplemente "obediencia" o "disciplina", que es como por lo general los traductores de la tragedia lo suelen traducir ${ }^{34}$. Sin embargo, creo que el concepto expresa más que eso. En efecto, la descomposición del término revela que está compuesto por el verbo peíthesthai, que significa "obedecer", y el sustantivo arkhé, que en el campo político significa "poder", "imperio" o "gobierno". Literalmente, entonces, peitharkhía quiere decir "el gobierno de la obediencia". Esto nos da la pauta de que la obediencia se presenta como un gran soberano que se impone en el seno de la comunidad y la estructura de acuerdo con un único principio: el principio de la obediencia. Además, este sentido de peitharkhía, como el gobierno de la obediencia, nos permite comprender por qué Creonte utilizó como ejemplos a la pólis, el ô̂kos y las filas de soldados, y no individuos en particular. La razón es clara: la peitharkhía opera en el plano de la colectividad, es decir, de asociaciones unificadas que conforman un cuerpo común, ya que ese gobierno es aquello que garantiza su existencia.

La peitharkhía es la máxima expresión política de la sumisión a la autoridad estatal, que se caracteriza por hacer del principio de la obediencia el valor más importante y el único criterio por el cual se puede juzgar cuándo una conducta es políticamente correcta: aquella que sirva a los fines de mantener la integridad de la pólis y la autoridad de los gobernantes. En este razonamiento, el principio de obediencia sobrepasa y se impone claramente por sobre el valor justicia ${ }^{35}$. Toda consideración moral queda desplazada de la escena política y no puede justificar ninguna causa de desobediencia: los fines políticos, como el orden y la seguridad, son el único norte al que debe aspirar el gobernante. Esta actitud del rey se corresponde con las palabras pronunciadas en los vv. 666-667, que enfatizan la necesidad de obedecer a quien gobierna en las cosas pequeñas, en las justas y en las contrarias.

Queda claro que, según Creonte, en la peitharkhía no hay lugar para la desobediencia. Si se diera espacio para ello en el campo político, esta clase de gobierno se desvanecería, ya que por definición la peitharkhía exige que el gobierno sea de la obediencia y de nada más. Recordemos -bajo riesgo de ser reiterativo- que no se trata de cualquier clase de obediencia. Es una obediencia de carácter absoluto que responde a un para qué muy importante: la preservación del orden social y la integridad de la comunidad política. En la visión de Creonte, la peitharkhía es el único medio de luchar contra la anarkhía. Sin embargo, el tirano no advierte que el estricto cumplimiento de $s u$ derecho tiene un costo muy alto.

El ejemplo que utiliza Hemón para explicar la actitud de Creonte reúne todas estas características de la tiranía, que están dominadas principalmente por los excesos o la falta de limitaciones (vv. 712-717).

30 Así pues, la peitharkhía se invoca como el claro opuesto de la anarkhía. Cf. Kamerbeek (1978, 130 ad vv. 673-676).

31 El uso de este vocablo también lo encontramos en A. Th. v. 224, Isoc.12.115, Pl. R. 538e3.

32 Cf. Liddell \& Scott (1996) y Bailly (2000) s.v. $\pi \varepsilon 1 \theta \alpha \rho \chi i ́ \alpha$.

33 Cf. Dindorf (1870); Ellendt (1965) s.v. $\pi \varepsilon 1 \theta \alpha \rho \chi i ́ \alpha$.

34 Cf. Jebb (1962 [1888], 129); Storr (1962, 367); Brown (1993, 77); Pinkler \& Vigo (1994, 96); Luca de Dios (2001, 200); Gibbons \& Segal (2003, 83); Alamillo (2006, 162); Schere (2011, 161); Mazon (2013, 55); Granero $(2014,103)$.

35 Cf. Harris $(2004,46)$. 


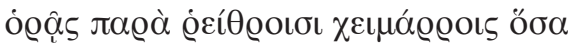

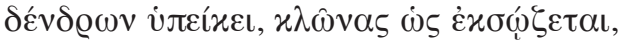

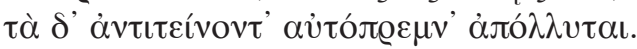

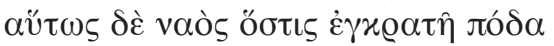

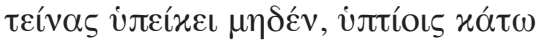

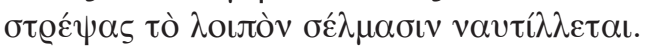

Sabes que junto a los lechos acrecentados por lluvias torrenciales cuantos árboles ceden salvan de este modo sus ramas; en cambio, los que resisten son destruidos junto con las raíces. Del mismo modo, quien mantiene tensa la escota de un barco y en nada cede, tras volcar, navega después con la cubierta al revés.

Este ejemplo no es más que un microcosmos de la tragedia de Creonte y resume la causa que lleva a la tiranía a su ruina. El tirano es aquel árbol que no cede a los torrentes o aquel navegante que no afloja las velas de la nave y termina con un destino funesto. Es aquel que no cede frente a ninguna fuerza exterior. En varias oportunidades Creonte recibió advertencias para desistir de su conducta; sin embargo, nada pudo modificar su posición jurídica acerca de la vigencia de su norma y su estricta aplicación. El exceso es una cualidad muy propia de su gobierno. Lo curioso es que esa obediencia incondicional es algo muy bien visto por Creonte, quien se jacta de no cometer ninguna falta si hace respetar su poder (v. 744). La sumisión absoluta a su autoridad es el mayor bien que su gobierno puede tener; desafiarlo, en cambio, es el peor mal. Esto es algo que el Coro explica claramente cuando afirma que "el poder [o la autoridad] de ninguna forma es transgredible para aquel quien

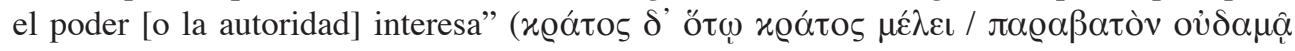
$\pi \varepsilon ́ \lambda \varepsilon l$, vv. 873-874). Ciertamente, tener autoridad supone el poder de exigir a aquellos sobre quienes se ejerce que cumplan con determinada conducta, incluso cuando tienen la posibilidad de no hacerlo ${ }^{36}$. Es el derecho que tiene el gobernante de exigir obediencia a los destinatarios ${ }^{37}$. No poder hacer efectivo el cumplimiento de ese derecho o, lo que es lo mismo, carecer de ese poder, supone una autoridad aparente, no real. En Critón de Platón encontramos un argumento similar al que instaló el Coro en la tragedia, que está vinculado con esta idea de mantener la autoridad del derecho y no permitir cualquier acto que la vulnere. Las Leyes personificadas de Atenas le dicen a Sócrates que ninguna pólis podría subsistir si las "sentencias" ( $\delta i ́ x a l)$ pronunciadas, en vez de ser cumplidas, fueran desauto-

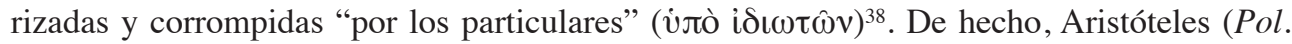
1322a5-8) consideraba la ejecución de la pena una instancia necesaria del proceso judicial, ya que las decisiones jurisdiccionales no tendrían ningún sentido y carecerían de provecho si no alcanzaran su cumplimiento.

36 Cf. Kojève (2006, 36).

37 De acuerdo con ello, entre la autoridad política y la obligación política existe una correlación. Cf. Pitkin (1966, 39-40); Raphael (1970, 78); Wolff (1998 [1971], 5); Raz (1981, 117 y 1985, 6); Fernández García (1994, 57); Finnis (2000, 261-288 y 2011, 82-87).

38 Pl. Cri. $50 \mathrm{~b} 4$. 
Sin embargo, en el caso de Creonte sucede prácticamente lo contrario de aquello que quieren resaltar Platón y Aristóteles. Es esa exigencia de cumplir firmemente con lo ordenado lo que arruina a la pólis y la priva de todo beneficio. En efecto, Tiresias será quien informe al tirano que a causa de su decisión la ciudad sufre grandes males (vv. 998 y ss.). Creonte no tendrá más remedio que seguir los consejos del Coro y abandonar la postura que mantuvo en la mayor parte de la obra: la "sentencia irrevocable", pues, será finalmente revocada. No es, por cierto, una renuncia firme y decidida, sino que es un acto llevado a cabo con reservas, ya que en la concepción que tiene el tirano acerca de cómo se debe ejercer el

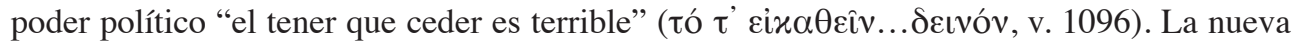
decisión, de todos modos, se toma demasiado tarde: es una posibilidad que se considera una vez que la norma fue cumplida y ha surtido todos sus efectos. El tirano necesitó ver los altares de la pólis tebana contaminados con los restos del cuerpo de Polinices, considerar la enemistad generada con las ciudades vecinas y también sufrir la muerte de su hijo y esposa como para darse cuenta que, al fin y al cabo, ha sido la obediencia absoluta a su kérygma la causa de su perdición.

\section{Conclusiones}

Creonte es la encarnación del ideal de la obediencia absoluta al derecho. Sin embargo, esto no es más que -en palabras de Fletcher $(2008,85)$ - una "fantasía del control absoluto" que terminará derrumbándose por completo. En efecto, el análisis del discurso de los personajes de Antígona revela que en ellos y en especial en la protagonista no existe una predisposición a obedecer a Creonte. No hay una verdadera convicción de que aquello que ordena sea justo y socialmente correcto.

El rey de Tebas se vale del miedo al castigo para obtener obediencia. Sin embargo, esto no es ningún mérito, pues la obediencia que se genera de manera violenta, denota la debilidad de su gobierno y su kérygma. No hay gobernante ni ley que se sostenga sólo por el temor de sus súbditos. El miedo es el fundamento más débil a la hora de constituir motivo de obediencia, ya que aquellos que se hallan sujetos a la ley, cuando ven la primera ocasión de salir impunes, no dudarán en transgredirla. Esto es lo que parece suceder con aquellos que según Creonte pagaban a otros para que se entierre a Polinices (vv. 293-294).

La obligación que se intenta imponer por medio de la coacción no es una genuina obligación hacia el gobernante con un correspondiente derecho de exigirles a los ciudadanos obediencia. La coacción, como sostiene Raphael (1970, 81-82), sólo nos permite afirmar que el ciudadano "está obligado" a obedecer, pero no resulta natural decir que en ese caso "tiene una obligación" e incluso sería inapropiado decir que "está bajo una obligación" hacia el gobernante o que éste tenga una derecho de recibir obediencia. Ya Welzel (2004 [1953], 198) decía que la coacción coacciona pero no obliga. Sólo un valor puede obligar y esa obligación es en última instancia de carácter moral.

El miedo suele ser una razón débil porque frente a una razón moral de mayor peso termina por ser derrotada con facilidad en el razonamiento destinado a elegir un curso de acción. De hecho, esto se aprecia con claridad en el caso de Antígona, quien decide desobedecer la norma en razón de la obligación que le imponen las leyes no escritas de los dioses. 


\section{Bibliografía}

\subsection{Ediciones, comentarios y traducciones}

Adams, C. D.ed. \& trad. (1958) The Speeches of Aeschines, Cambridge: Harvard University Press (Loeb Classical Library).

Alamillo, A. trad. (2006) Sófocles. Tragedias, Barcelona: Gredos.

Brown, A. ed. (1993) Sophocles: Antigone, Warminster, UK: Aris \& Phillips.

Brownson, C. L. ed. \& trad. (1918-1921) Xenophon. Hellenica, 2 vol., Cambridge: Harvard University Press (Loeb Classical Library).

Burnet, J. ed. (1900) Respublica. Platonis Opera, Tomo IV, Oxford: Clarendon Press.

Burnet, J. ed. (1929) Plato's Euthyphro, Apology of Socrates and Crito, Oxford: Clarendon Press.

Diels, H. \& Kranz, W. eds. (1960) Die Fragmente der Vorsokratiker, 3 vols., Berlin: Weidmannsche Buchhandlung.

Dilts, M. R. ed. (2002-2009) Demosthenis Orationes, 4 vols., Oxford: University Press.

Duke, E. A., Hicken, W. F., et al. eds. (1995) Politicus. Platonis Opera, Tomo I, Oxford: Clarendon Press.

Gibbons, R. \& Segal, C. trads. (2003) Sophocles: Antigone, Oxford: University Press.

Jaerisch, P. ed. (1987) Xenophon, Erinnerungen an Sokrates, München: Artemis Verlag.

Jebb, R. C. ed. (1962 [1888]) Sophocles. The Plays and Fragments. Part III: The Antigone, Amsterdam: Adolf M. Hakkert.

Jones, H. S. ed. (1898-1902) Thucydidis Historiae, 2 vols., Oxford: University Press.

Louis, P. ed. \& trad. (1961) Aristote. De la génération des animaux, Paris: Les Belles Lettres.

Luca de Dios, J. M. trad. (2001) Sófocles: Áyax, Las Traquinias, Antígona y Edipo Rey, Madrid: Alianza.

Marías, J. \& Araujo, M. eds. \& trads. (1951) Aristóteles. Política, Madrid: Instituto de Estudios Políticos.

Mazon, P. ed. \& trad. (2013) Sophocle. Antigone, Paris: Les Belles Lettres.

Murray, G. ed. (1902-1909) Euripidis Fabulae, 3 vols. Oxford: Clarendon Press.

Murray, G. ed. (1960) Aeschyli: Septem Quae Supersunt Tragoediae, Oxford: Clarendon Press

Norlin, G. ed. \& trand. (1954) Isocrates, 3 vols., London: Heinemann (Loeb Classical Library).

Pearson, A.C. ed. (1957) Sophoclis Fabulae, Oxford: Clarendon Press.

Pinkler, L. \& Vigo, A. trads. (1994) Sófocles. Antígona, Buenos Aires: Biblos.

Schere, J. trad. (2011) Sófocles. Edipo rey, Edipo en Colono, Antígona, Buenos Aires: Colihue.

Storr, F. ed. \& trad. (1962) Sophocles: Oedipus the King, Oedipus at Colonus, Antigone, vol. 1, London: Heinemann (Loeb Classical Library).

\subsection{Bibliografía secundaria}

Adams, S. M. (1955) "The Antigone of Sophocles", Phoenix, vol. 9, n², pp. 47-62.

Austin, J. (1998 [1832]) The Province of Jurisprudence Determined and The Uses of the Study of Jurisprudence, Indianapolis/Cambridge: Hackett Publishing Company Inc.

Bieda, E. (2008) “Antifonte sofista: un utilitarismo naturalista”, Méthexis, n² 21, pp. 23-42. 
Blundell, M. W. (1989) Helping Friends and Harming Enemies: A Study in Sophocles and Greek Ethics, Cambridge: University Press.

Bobbio, N. (1965) El problema del positivismo jurídico, Buenos Aires: Eudeba.

Boedeker, D. \& Raaflaub, K. (2005) "Tragedy and the City", en R. Bushnell (ed.) A Companion to Tragedy, Oxford: Blackwell, pp. 109-127.

Bowra, C. M. (1944) Sophoclean Tragedy, Oxford: Clarendon Press.

Boyd, C. B. (1952) “The Isolation of Antigone and Lady Macbeth", The Classical Journal, Vol. 47, n 5, pp. 174-177.

Burns, T. (2002) "Sophocles' Antigone and the History of the Concept of Natural Law", Political Studies, vol. 50, pp. 545-557.

Cantarella, E. (1996) Los suplicios capitales en Grecia y Roma, Madrid: Akal.

Carter, D. (2012) “Antigone”, en Markantonatos, A. (ed.) Brill's Companion to Sophocles, Leiden: Brill, pp. 111-128.

Cerri, G. (1979) Legislaziones orale e tragedia greca. Studi sull' Antigone di Sofocle e sulle Supplici di Euripide, Napoli: Liguori.

de Oliveira, J. D. (2013) "O discurso de Creonte na Antígona de Sófocles", Fragmentum, vol. $1, \mathrm{n}^{\circ} 38$, pp. 85-96.

de Romilly, J. (2004) La ley en la Grecia clásica, Buenos Aires: Biblos.

Eggers Lan, C. (1986) "En torno al origen de la noción de ley en Grecia", Anuario de filosofía jurídica y social, $\mathrm{n}^{\circ}$ 6, pp. 35-45.

Errandonea, I. (1942) Sófocles y su teatro, Tomo 1, Madrid: Escelicer.

Ferguson, A. R. (1974-1975) "Politics and Man's Fate in Sophocles' Antigone", The Classical Journal, vol. 70, n², pp. 41-49.

Fernández García, E. (1994) La obediencia al Derecho, Madrid: Editorial Civitas.

Finnis, J. (2000) Ley Natural y Derechos Naturales, Buenos Aires: Abeledo-Perrot.

Finnis, J. (2011) "Positivism and 'Authority", en Philosophy of Law. Collected Essays, vol. IV, Oxford: University Press, pp. 74-87.

Fletcher, J. (2008) "Citing the Law in Sophocles's Antigone", Mosaic, vol. 41, n 3, pp. 79-96.

Foley, H. (1995) “Tragedy and Democratic Ideology: The Case of Sophocles' Antigone”, en Goff, B. (ed.) History, Tragedy, Theory: Dialogues on Athenian Drama, Austin: University of Texas Press, pp. 131-150.

García-Huidobro, J. (1998) “Antígona: el descubrimiento del límite”, Persona y derecho: Revista de fundamentación de las Instituciones Jurídicas y de Derechos Humanos, $\mathrm{n}^{\circ}$ 39, pp. 85-108.

Goldhill, S. (1986) Reading Greek Tragic, Cambridge: University Press.

Harris, E. M. (2004) “Antigone the Lawyer, or the Ambiguities of Nomos," en Harris, E. M. \& Rubinsten, L. (eds.) The Law and the Courts in Ancient Greece, London: Duckworth, pp. 19-56.

Hegel, G. W. F. (2007 [1807]) Fenomenología del espíritu, Buenos Aires: F.C.E.

Hobbes, T. (2007 [1651]) Leviatán: o la materia, forma y poder de una república eclesiástica y civil, Buenos Aires: F.C.E.

Jaeger, W. (2010 [1933]) Paideia: los ideales de la cultura griega, México: F.C.E.

Kelsen, H. (1949) Teoría General del Derecho y del Estado, México: Imprenta Universitaria. 
Kelsen, H. (1994 [1953]) Teoría pura del derecho, Buenos Aires: Eudeba.

Kelsen, H. (2011 [1934]) Teoría pura del derecho. Introducción a los problemas de la ciencia jurídica, primera edición, Madrid: Editorial Trotta.

Knapp, C. (1916) "A Point in the Interpretation of the Antigone of Sophocles", The American Journal of Philology, vol. 37, $\mathrm{n}^{\circ}$ 3, pp. 300-316.

Knox, B. M. W. (1964) The Heroic Temper. Studies in Sophoclean Tragedy, Berkeley: University of California Press.

Kojève, A (2006) La noción de autoridad, Buenos Aires: Nueva Visión.

Lane, W. J. \& Lane, A. M. (1986) "The Politics of Antigone", en Euben, J. P. (ed.) Greek Tragedy and Political Theory, Berkeley: University of California Press, pp. 162-182.

Lanza, D. (1997) Le tyran et son public, Paris: Belin.

Levy, C. S. (1963) “Antigone's Motives: A Suggested Interpretation”, Transactions and Proceedings of the American Philological Association, vol. 94, pp. 137-144.

Mastromarco, G. \& Totaro, P. (2008) Storia del teatro greco, Firenze: Le Monnier.

Nonet, P. (2006) “Antigone's Law”, Law, Culture and the Humanities, vol. 2, pp. 314-335.

Orsi, R. (2007) El saber del error: filosofía y tragedia en Sófocles, Madrid: Plaza \& Valdés.

Parker, R. (1996) Miasma. Pollution and Purification in Early Greek Religion, Oxford: Clarendon Press.

Parker, V. (1998) "Tú @avvos. The Semantics of a Political Concept from Archilochus to Aristotle", Hermes, vol. 126, n 2, pp. 145-172.

Parodi Remón, C. (2004) "El derecho en Antígona, ¿natural o positivo?, Dikaiosyne, n 12 , $\mathrm{s} / \mathrm{n}$.

Picco, F. (1999) La Tragédie grecque: la scène et le tribunal, Paris: Michalon.

Pitkin, H (1966) "Obligation and Consent II", The American Political Science Review, vol. $60, \mathrm{n}^{\circ} 1, \mathrm{pp} .39-52$.

Plescia, J. (1976) "Sophocles' Antigone: Creon or Tyranny on Trial”, Aevum, vol. 50, n $1 / 2$, pp. 129-136.

Raaflaub, K. A. (2003) "Stick and Glue: The Function of Tyranny in Fifth-Century Athenian Democracy”, en Morgan, K. A. (ed.) Popular Tyranny: Sovereignty and its Discontents in Ancient Greece, Austin: University of Texas Press, pp. 59-93.

Raphael, D. D. (1970) Problems of Political Philosophy, New York: Praeger Publishers, Inc.

Raz, J. (1981) “Authority and Consent”, Virginia Law Review, vol. 67, n 1, pp. 103-131.

Raz, J. (1985) "Authority and Justification”, Philosophy \& Public Affairs, vol. 14, n 1 , pp. 3-29.

Rivas Palá, P. (1996) Justicia, comunidad y obediencia. El Pensamiento de Sócrates ante la ley, Pamplona: EUNSA.

Robert, W. (2010) “Antigone's Nature”, Hypatia, vol. 25, n² 2, pp. 412-436.

Rosenfield, K. H. (2002) Sófocles e Antígona, Río de Janeiro: Zahar.

Ross, A. (2008) "El concepto de validez y el conflicto entre el positivismo jurídico y el derecho natural", Academia. Revista sobre enseñanza del Derecho, año 6, n 12, pp. 199-220.

Santamaría, A. L. (2009) Implicancia éticas de la Antígona de Sófocles. Una reflexión sobre el pensamiento trágico griego, Madrid: Plaza \& Valdés.

Seaford, R. (2003) “Tragic Tyranny”, en Morgan, K. A. (ed.) Popular Tyranny: Sovereignty and its Discontents in Ancient Greece, Austin: University of Texas Press, pp. 95-115. 
Segal, C. (1964) "Sophocles' Praise of Man and the Conflicts of the Antigone", Arion: A Journal of Humanities and the Classics, vol. 3, $\mathrm{n}^{\circ} 2$, pp. 46-66.

Segal, C. (1999 [1981]) Tragedy and Civilization. An Interpretation of Sophocles, Norman, Okla.: University of Oklahoma Press.

Soares, L. (2002) Anaximandro y la tragedia. La proyección de su filosofía en la Antígona de Sófocles, Buenos Aires: Biblos.

Sourvinou-Inwood, C. (1989) "Assumptions and the Creation of Meaning: Reading Sophocles' Antigone," The Journal of Hellenic Studies, vol. 109, pp. 134-148.

Thomas, R. (1996) "Written in stone? Liberty, Equality, Orality and the Codification of Law," en Foxhall, L. \& Lewis, A. D. E. (eds.) Greek Law in its Political Setting: Justifications not Justice, Oxford: Clarendon Press, pp. 9-31.

Tiefenbrun, S. W. (1999) "On Civil Disobedience, Jurisprudence, Feminism and the Law in the Antigones of Sophocles and Anouilh", Cardozo Studies in Law and Literature, vol. $11, \mathrm{n}^{\circ} 1$, pp. 35-51.

Tyrrell, W. B. \& Bennett, L. J. (2008-2009) “Sophocles's Enemy Sisters: Antigone and Ismene", Contagion: Journal of Violence, Mimesis, and Culture, vol. 15/16, pp. 1-18.

von Wright, G. H (1970) Norma y Acción. Una investigación lógica, España: Tecnos.

Welzel, H. (2004 [1953]) “Derecho natural y positivismo jurídico", en Estudios de Filosofía del Derecho y Derecho Penal, Buenos Aires: B de F, pp. 177-199.

Wolff, R. P. (1998 [1971]) In Defense of Anarchism, Berkeley: University of California.

Worman, N. (2012) "Oedipus, Odysseus, and the Failure of Rethoric", en Markantonatos, A. (ed.) Brill's Companion to Sophocles, Leiden: Brill, pp. 325-347.

\subsection{Instrumenta Studiorum}

Bailly, A. (2000) Dictionnaire Grec-Français, Paris: Hachette.

Beekes, R. (2010) Etymological Dictionary of Greek, 2 vols., Leiden: Brill.

Chantraine, P. (1999) Dictionnaire étymologique de la langue grecque. Histoire des mots, Paris: Klincksieck.

Dindorf, W. (1870) Lexicon Sophocleum, Lipsiae: Teubner.

Ellendt, F. T. (1965) Lexicon Sophocleum, Hildesheim: Georg Olms.

Gantz, T. (1993) Early Greek Myth: A Guide to Literary and Artistic Sources, London: Johns Hopkins University Press.

Liddell, H. G. \& Scott, R. (1996) A Greek-English Lexicon, Oxford: Clarendon Press.

Smyth, H. W. (1984) Greek Grammar, Cambridge: Harvard University Press. 